\title{
CHIP SHOTS: \\ ASSOCIATION BETWEEN THE \\ STATE CHILDREN'S HEALTH INSURANCE PROGRAMS AND IMMUNIZATION COVERAGE AND DELIVERY
}

\author{
Ted Joyce \\ Andrew Racine \\ Working Paper 9831 \\ http://www.nber.org/papers/w9831 \\ NATIONAL BUREAU OF ECONOMIC RESEARCH \\ 1050 Massachusetts Avenue \\ Cambridge, MA 02138 \\ July 2003
}

\begin{abstract}
The views expressed herein are those of the authors and not necessarily those of the National Bureau of Economic Research

(C2003 by Ted Joyce and Andrew Racine. All rights reserved. Short sections of text not to exceed two paragraphs, may be quoted without explicit permission provided that full credit including (C) notice, is given to the source.
\end{abstract}


Chip Shots: Association Between the State Children's Health Insurance Programs and Immunization Coverage and Delivery

Ted Joyce and Andrew Racine

NBER Working Paper No. 9831

July 2003

JEL No. I18

\begin{abstract}
By age two a child who is up to date for immunizations will have received up to 19 shots delivered over eight visits at a market cost of $\$ 525$ dollars for the vaccines alone, a far more expensive and demanding regimen that the 8 shots received in 1987. In recognition of the potential importance of health insurance to immunization coverage rates, the State Children's Health Insurance Program (SCHIP) mandated that all plans cover the cost and administration of childhood vaccines. We use data from the recently released National Immunization Survey for the years 1995 to 2001 to test whether SCHIP was associated with differential changes among poor and near-poor children relative to their non-poor counterparts in either age-appropriate immunization rates or in the proportion of vaccines delivered by private providers. We show that the probability that a child was up to date for the varicella vaccine increased between 7 and 16 percentage points more among poor and near-poor relative to non-poor children after implementation of SCHIP. The increase was greater among children from urban areas, among Hispanics and among those from states with the highest rates of uninsured children prior to SCHIP than among children nationally. We found small to inconsequential changes for other vaccines. We also found that the probability that a poor or near-poor child obtained all vaccines at a private provider fell relative to the same probability among non-poor children over the study period. SCHIP appears to have affected the uptake of a recently introduced vaccine, which suggests that insurance coverage may be important for the rapid adoption of the latest and increasingly more expensive agents such as the pneumococcal conjugate vaccine.
\end{abstract}

Ted Joyce

National Bureau of Economic Research

365 Fifth Avenue, 5th Floor

New York, NY 10016

and Baruch College, CUNY

Ted_Joyce@baruch.cuny.edu
Andrew Racine

National Bureau of Economic Research

365 Fifth Avenue, 5th Floor

New York, NY 10016

and the Montefiore Medical Center

aracine@montefiore.org 


\section{Introduction}

The Balanced Budget Act of 1997 established the State Children's Health Insurance Program or SCHIP. The Program makes available health insurance to children in near-poor families that are ineligible for Medicaid. The 40 billion dollars appropriated over ten years for SCHIP represents the largest extension of publicly provided health insurance since Medicaid. The motivation came from the high rates of uninsured children among the working poor. Approximately, 23 percent of children from families with incomes between 100 and 200 percent of the federal poverty level (FPL) and 27 percent of children in poverty lacked health insurance in 1996 (Dubay, Kenny and Haley 2000). A recent analysis indicates that the proportion of children without insurance for some part of the year may be as high as 40 percent (Congressional Budget Office 2003).

Efforts to evaluate SCHIP have largely focused on take up rates (Dubay, Kenny and Haley 2000; LoSasso and Buchmueller 2002). The few studies of outcomes pertain to the precursors of SCHIP in selected states and have focused primarily on changes in utilization (Lave et al. 1998 ; Szilagyi et al. 2000a). There is a more extensive literature on the effect of the Medicaid eligibility expansions on health care utilization (Currie and Gruber 1996; Newacheck et al. 1998; Kaestner, Racine and Joyce 2001; Racine et al. 2001; Lykens and Jargowsky 2002). Most researchers have found a positive association between enrollment in Medicaid or expansions in Medicaid eligibility and doctor's visits, hospital admissions and access to a regular source of pediatric care. While it is tempting to infer from these results that increased utilization leads to better health, the measures of utilization are often too general to draw causal links ${ }^{1}$.

\footnotetext{
${ }^{1}$ The lack of health outcomes sufficiently sensitive to changes in insurance has been a long standing problem in attempts to associate insurance and health (Levy and Meltzer 2001) [I don't see this referenced at the end of the paper].
} 
Despite the utilization findings, few studies have been able to demonstrate a convincing association between changes in insurance and changes in children's health (Currie and Gruber 1996; Kenny, Dubay and Haley 2000; Szilagyi et al. 2000b;Lykens and Jargowsky 2002). The infrequency of adverse health events and the invariance of self-reported health have limited the power to detect associations.

In this study we look at the association between SCHIP and childhood immunization rates. We also examine whether children receive vaccines from a single provider, a single private provider or one that provides comprehensive pediatric services. Vaccines are a particularly useful outcome by which to assess SCHIP. First, immunization rates are a unique measure of utilization because the link between the receipt of vaccines and prevention of vaccine preventable illnesses is so direct. Second, SCHIP legislation specifically mandates that all state programs cover the cost and administration of all childhood vaccines as recommended by the Advisory Committee on Immunization Practices. ${ }^{2}$ Third, immunization rates may be particularly sensitive to the ability to pay. The cost of vaccines has increased dramatically over the past ten years. It now costs $\$ 525$ at market prices for vaccines alone to fully immunize a child by age two. In addition, there are now up to 19 shots given in the first two years and administered over eight visits. The number of vaccines and the complexity of vaccine schedules make up-to-date coverage rates a particularly apt indicator of the quality of primary pediatric care. Lastly, the site at which vaccines are received is also important since each visit offers opportunities for general health screening, developmental assessment, injury prevention counseling, nutritional guidance, parenting advice and other elements of systematic well-child care. Children

\footnotetext{
${ }^{2}$ See http://cms.hhs.gov/schip/ch062599.asp
} 
vaccinated in public health clinics that do not offer comprehensive pediatric services may not obtain these important assessments.

This study is the first to associate changes in the availability of insurance to immunization rates at the national level. The expense and complexity associated with the documentation of immunizations has limited the scope of previous studies. The recent release of the National Immunization Survey (NIS) has made a national study possible. The NIS is a yearly population-based survey of more than 30,000 households per year with children between 19 and 35 months of age. The NIS has information on vaccine receipt, characteristics of the providers as well as social and economic measures of the household. The availability of this data set enables us to address three questions. 1) Are changes in the timing of implementation and generosity of state SCHIP income thresholds associated with changes in immunization coverage rates among poor and near-poor children? 2) Is the establishment of SCHIP associated with changes in the probability that a poor or near-poor child obtains vaccines from a private provider or one that offers comprehensive services? 3) How does the availability of publicly provided health insurance affect uptake rates of newly introduced vaccines among poor and near-poor children.

\section{Background}

US vaccination policy in the 1990s was in large part a response to the resurgence of measles in the beginning of the decade. In 1990, the peak year of the resurgence, the incidence of measles for children less than 5 years of age was 15 times greater than the median incidence between 1981 and 1988. All totaled, there were over 55,000 cases of measles, 11,000 hospitalizations and 166 deaths between 1989 and 1991 (Centers for Disease Control and Prevention 1992). The greatest concentration of cases occurred among minority, pre-school 
children in urban centers. In its assessment of the epidemic, the National Vaccine Advisory Committee blamed the low rate of vaccination at the recommended age (National Vaccine Advisory Committee 1991).

The costs of vaccines and inadequate access to pediatric care were viewed as significant barriers to early immunization. In 1993, the Clinton Administration launched the Childhood Immunization Initiative, which set goals for coverage rates, outreach, education and financial support. The Vaccine for Children Program (VFC) was implemented in October of 1994 and makes free vaccines available through providers to children 18 years of age or younger who are eligible for Medicaid, uninsured, Native American or Alaskan Native, or who are underinsured and who receive services at a federally qualified health care center (Institute of Medicine 2000). SCHIP, with its specific mandate regarding coverage of immunizations, was part of the general thrust to insure adequate vaccination rates.

The availability of free vaccines and the expansion in health insurance for poor and nearpoor children comes at a propitious juncture given the number and costs of vaccinations. There are now 19 doses of vaccines that an infant should receive, within the first 18 months (MMWR 2002), up from 8 in 1987. Costs of vaccines to fully immunize a child have risen from $\$ 116$ in 1987 at private sector prices to $\$ 525$ in $2002^{3}$. It is estimated that the administration of vaccines costs add an additional \$15 per shot in 1995 (Institute of Medicine 2000). The new varicella and pneumococcal vaccines cost approximately $\$ 45.00$ per dose making them four to five times more expensive than either the combined vaccine for diphtheria, acellular pertussis and tetanus (DaPt) or the inactivated vaccine for polio (IPV). The Institute of Medicine speculates that the

\footnotetext{
${ }^{3}$ Figures for 1987 are from the Institute of Medicine (2000). Figures for 2002 are based on authors' calculations using prices posted by the Centers for Disease Control and Prevention, (http://www.cdc.gov/nip/vfc/cdc_vac_price_list.htm).
} 
number of vaccines could triple within the next 20 years (Institute of Medicine 2000), although new combination vaccines may serve to simplify the regimen over time ${ }^{4}$.

Growth in the complexity and the cost of the childhood vaccine schedule underscores the importance of realized access to comprehensive pediatric care since sporadic visits to a health care provider are increasingly less likely to result in complete immunization coverage than before. In this context, the availability of health insurance plays an important role since the cost of pediatric health care is a significant determinant of its use. The effect of health insurance on the utilization of health care services by children is well-established (Newhouse et al. 1993; Currie and Gruber 1996; Newacheck et al. 1998a; Dubay and Kenney 2001). Health insurance is also associated with children having a regular source of care (Newacheck et al. 1998b).

Unsurprisingly, therefore, health insurance is related to appropriate vaccination rates (Lurie et al. 1987). In a more recent analysis of how financial incentives matter, researchers used a randomized design to study the effect of making receipt of welfare benefits contingent upon pre-school children being up to date for immunizations. Children in the experimental group were approximately 4 to 6 percentage points more likely to be up to date than children from families unexposed to the sanction (Kerpelman, Connell and Gunn 2000).

There is also evidence that the extension of health insurance to near-poor families is associated with increased immunization coverage rates, although it is unclear whether the relationship is a causal one. Researchers examined the effect of New York State's Child Health Plus (CHPlus) program in 1991, a model for the current SCHIP (Rodewald et al. 1997). Using a

\footnotetext{
${ }^{4}$ See, for example, the recent introduction of a combination vaccine for diphtheria and tetanus toxoids, acellular pertussis adsorbed, Hepatitis B (recombinant) and poliovirus by GlaxoSmithKline called Pediarix ${ }^{\mathrm{TM}}$ (Centers for Disease Control, 2003).
} 
pre-post design, they found that up-to-date immunizations among those that had no insurance prior to CHPlus increased 5.8 percentage points after implementation. However, there was a similar increase among those who were always insured (4.0 percentage points). Thus, it was unclear whether the increase was attributable to CHPlus or general trends in coverage.

Another focus of recent work has been the effect of insurance or free vaccines on where vaccines are received. A survey of physicians found that those who participated in the VFC program were less likely to refer uninsured and Medicaid patients to the local health department (Zimmerman et al. 1997; Szilagyi et al. 2000). A similar survey before and after implementation of the VFC program reported a statistically significant decline in referrals of the uninsured to public clinics associated with VFC in Pennsylvania, but not in Minnesota (Zimmerman et al. 2001). In New York State, researchers reported that the number of childhood vaccines administered by state health departments fell more than 50 percent between 1991 and 1996, years that bracket the introduction of the VFC and so called First Dollar Laws (Szilagyi et al. 2000).

In summary, there is evidence that the cost of vaccines and the lack of health insurance are significant barriers to the receipt of immunizations in a "medical home." What is unclear is how immunization rates and sites of delivery have changed over the past eight years and how much of the change is associated with the growth in publicly provided health insurance. Although SCHIP has been targeted at children from near-poor families, aggressive outreach programs have also increased enrollment of children in Medicaid as well (Mann et al. 2002). Thus, we examine changes among poor and near-poor children. 


\section{Empirical Implementation}

\section{The National Immunization Survey}

The National Immunization Survey (NIS) is a national probability sample of children ages 19 to 35 months. There are 78 Immunization Action Plan areas representing 50 states and 28 metropolitan areas in the sample. Each IAP is a stratum and households are drawn randomly within each stratum. Approximately 420 households are surveyed in each stratum each year for a total of about 34,000 households annually. The survey uses a random-digit-dialing (RDD) design to identify households with children of the appropriate age and to survey them by phone. A person most knowledgeable about the child's immunizations is asked to be the respondent. Each respondent is asked to locate a shot card if available. In addition to information on the number and date of vaccines, respondents are asked about maternal schooling, family income, marital status, and other socio-demographic information. ${ }^{5}$ Respondents are then asked permission to contact their immunization providers. The second survey within the NIS is the provider record check (PRC). Providers are mailed a survey in which they are asked to furnish the child's vaccination history. The initial mailing is followed up with reminders and telephone calls. The 79 percent household response rate is impressively high for a RDD survey (Smith et al. 2001), as is the $94.6 \%$ response rate of providers questionnaires in 1999 .

The provider data are generally considered the most reliable. However, complete provider data are obtained for approximately 65 percent of the 34,000 households surveyed. Those with complete provider data are more likely to be white, better educated, and have greater incomes than households without provider data. Aware of the potential problems associated with selective reporting, administrators of the NIS use propensity scores within each stratum to adjust

\footnotetext{
${ }^{5} \mathrm{~A}$ list of the key variables is provided on page 40 of the User's guide ( $\mathrm{http}: / / \mathrm{www} . \mathrm{cdc} . \mathrm{gov} / \mathrm{nis} / \mathrm{pdfs} / \mathrm{nisdug} 01 . \mathrm{pdf}$ ).
} 
sampling weights for households with non-provider data (Smith et al. 2001). The provider survey is the only source of information on the type of provider (e.g., public, private, VFC, etc.) and thus, generalizations as to the impact of SCHIP on where children obtain their immunizations is limited to this sample. ${ }^{6}$ However, we also use the household survey for analyses related to the probability of being up to date for various vaccines. We use all respondents with complete provider data as well as those who use a shot card to recall vaccines. There is good evidence that shot cards provide reliable information regarding vaccines, but that parental recall alone does not (Fierman et al. 1996; Suarez, Simpson, Smith 1997). We assume that there are no false positives on either the shot card or provider survey. Thus, if a child is reported up-to-date for a vaccine based on either the shot card or the provider survey, then we assume that the child is up to date for that vaccine. In Table 1 of the Appendix we provide a breakdown of the source of immunization information for the full seven year sample selected characteristics of the child or family.

\section{State Children Health Insurance Program}

The purpose of SCHIP is to extend health insurance to children in near-poor families that do not qualify for Medicaid, but who are uninsured. ${ }^{7}$ Prior to SCHIP, Medicaid eligibility levels for all children up to age 6 were at least at 133 percent of the federal poverty level by law. States had the option of raising them to virtually any level through provisions embodied in Section

\footnotetext{
${ }^{6}$ The household survey asks each respondent how many vaccine providers they used. We use those who saw only one provider as a positive indicator of continuity. It is the only provider measure available from the household survey.

${ }^{7}$ In constructing SCHIP states have the option of extending Medicaid, creating a new insurance program or a combination of both. Eighteen states and D.C. chose to extend Medicaid (M-SCHIP), 15 established separate programs (S-SCHIP) and 17 had combinations (C-SCHIP). Evidence suggests that the distinction between MSCHIP and S-SCHIPS is not important with respect to its impact on the lack of insurance among children (Buchmueller and LoSasso 2002). Consequently we do not analyze differences by program type.
} 
$1902 ®(2)$ of the Social Security Act and still receive federal cost-sharing. SCHIP allows states to raise the income eligibility thresholds above the Medicaid thresholds up to any level. ${ }^{8}$

We specify SCHIP in several ways. First, we use dummy variables to capture the timing of program implementation for children zero to five years of age. For instance, 8 states began enrollment of children in 1997, 33 in 1998, 8 in 1999 and 2 in 2000 (Rosenbach et al. 2001). We also use income eligibility thresholds to measure variation in generosity. As of 2001, 14 states had established income eligibility limits for children 1 to 5 years of age at above 200 percent of the federal poverty level (FPL), 26 states at 200 percent of FPL and 11 at less than 200 percent. ${ }^{9}$ For years prior to SCHIP we use the Medicaid eligibility threshold for children 0 to 5 years of age. Figure 1 displays average income eligibility thresholds for infants and children one to five years of age. The important point is that prior to SCHIP eligibility for infants was substantially greater than was eligibility for children and the thresholds of the two age groups do not merge until 2000. We use differences in the age of the child and differences in income eligibility thresholds between infancy and childhood as an additional source of variation. Specifically, the NIS has three categories for the child's age: 19 to 23 months, 24 to 29 months and 30 to 35 months. Most vaccines are initiated in infancy. Measles, mumps and rubella (MMR) and varicella vaccines begin at 12 months of age. Consequently, the relevant income threshold is the one in place at the time vaccines are scheduled to begin. Consider a child 19 to 23 months in Massachusetts in 1998. Use the median age of 21 months. We assume that the child spends 12 of the 21 months (0.57) exposed to the threshold for infants in 1997 and 9 of 21

\footnotetext{
${ }^{8}$ Initially, eligibility thresholds under SCHIP were only allowed up to 200 percent of the federal poverty level (FPL) or 50 percent above the minimum threshold that existed as of March 1997. Soon after implementation of the plan this restriction was lifted due to a determination that Section 1902®(2) applied to SCHIP.

${ }^{9}$ Data on eligibility thresholds are from Lisa Dubay of the Urban Institute in Washington, D.C.
} 
months (0.43) exposed to the children's eligibility level in 1998. Thus, the average income eligibility threshold for this child is the weighted average of the Massachusetts's threshold for infants in 1997 plus the threshold for children in 1998 with weights of 0.57 and 0.43 , respectively. We follow an analogous procedure for infants 24 to 29 and 30 to 35 months and we modify the algorithm for vaccines that begin at 12 months.

The NIS has measures of family income but they are not sufficiently refined so as to accurately measure eligibility for Medicaid and SCHIP. There are 9 categories of income in the 1995-1998 surveys and 15 categories in the 1999-2002 surveys. The NIS uses an algorithm based on reported family income and family size to create an indicator of poverty status defined as below 100 percent of the federal poverty level. In 1999, the NIS added a new variable that measures the ratio of income to poverty. To create a consistent series of income to poverty, we used the income categories and family size to create an income to poverty ratio for $1995-1998 .^{10}$ We then defined three categories of family: poor or those with $<100$ percent of the FPL; nearpoor or those with income $>=100$ and $<250$ percent of the FPL; and non-poor those with income $>=250$ percent of the FPL and a separate category for unknown income. We use these as broad measures of eligibility to define exposure to SCHIP.

The effect of SCHIP on immunizations should vary by proportion of uninsured and underinsured children among the poor and near-poor as well as the pre-SCHIP level of immunization coverage rates. For example, between 23 and 27 percent of near-poor and poor children respectively lacked health insurance in 1996, based on the Current Population Survey (Dubay, Hill and Kenny 2002). However, such point-in-time calculations substantially

\footnotetext{
${ }^{10}$ As a check on our measure, we used our algorithm to compute poverty status $(<100 \mathrm{FPL})$ and compared our poverty indicator to the one computed by NIS. The associated kappa statistic ranged from .93 to .99 between 1995 and 1998.
} 
underestimate the proportion of children that are uninsured for part of the year and overestimate children without insurance for the entire year (Congressional Budget Office 2003). Furthermore, it is unclear how many children are "underinsured" by policies that do not cover some or all vaccines (Institute of Medicine 2000). In addition, the rate of uninsured children varies substantially by state. Data from the National Survey of American Families (NSAF), for instance, indicate that 34 percent of children from families with income below 200 percent of the FPL in Texas lacked insurance in 1997 as compared with 13.8 percent in Massachusetts (Kenny, Dubay and Haley 2000). Finally, the measles epidemic was largely an urban phenomenon, concentrated in Los Angeles, Houston and Chicago among primarily poor and Hispanic children (National Vaccine Advisory Committee 1991). To exploit these potential interactions, we present a series of analyses by states with high and low rates of uninsured children, by urban areas specifically designated as immunization action plan areas (IAP) by the NIS and by Hispanics. ${ }^{11}$

\section{Outcomes}

Our analysis concentrated on two policy relevant domains: the site where immunizations occurred and the likelihood of the child being up-to-date with immunizations. Specifically with regard to the site of immunization receipt, we were interested in the degree to which SCHIP increased the probability of receiving all immunizations from a single provider as a surrogate marker of enhanced continuity of care. As additional markers of pediatric care we subdivided single providers into private and public to test whether SCHIP was associated with shifts from public to private practice settings. We also tested whether SCHIP was associated with an increased probability of receiving vaccines at a comprehensive pediatric provider, regardless of

\footnotetext{
${ }^{11}$ The CDC targeted selected urban areas with underserved populations. Although these areas were to receive
} 
public or private status. This indication was added to the NIS in 1997. Comprehensiveness is an important characteristic of pediatric health care indicating that, in addition to immunizations, children are receiving appropriate screening, developmental evaluation, nutrition assessment, behavioral counseling and other components of high quality preventive care. For each of these outcomes we compared the experience of poor and near-poor children with the trends among their non-poor counterparts. We hypothesized that an SCHIP effect on these outcomes would be most pronounced among near-poor children, but that we might also see an association with poor children as a spillover effect from SCHIP outreach initiatives.

The second domain we investigated was the probability of being up-to-date with immunizations. For the SCHIP, immunization receipt may be seen as an indirect marker of realized access to timely care. The public use NIS provides data on individual immunizations as well as combinations. We focus on two series of vaccines and two individual vaccines. The accepted definition of being up-to-date with immunizations during the years we studied was to have received four diphtheria, tetanus and acellular pertussis vaccines (DtaP), three polio vaccines, one measles containing vaccine, and three Haemophilus influenza vaccines by eighteen months of age (http://www.cdc.gov/nip/publications/ACIP-list.htm). For this reason we use this 4:3:1:3 series as an important outcome of interest.

The other series we use is the Hepatitis B series of three vaccinations by eighteen months of age. Since many children actually receive all three of these vaccinations before a year of age, this series helps to characterize the immunization experience of infants during the first year of life more selectively than the 4:3:1:3 series part of which is not to be given before a year of age. In addition, the Hepatitis B vaccine is relatively new, recommended by the ACIP for all infants 
in November of 1991(Centers for Disease Control and Prevention 1991). As such, it may indicate how well new vaccines disseminate among different populations of children.

We also chose to consider two individual vaccines as outcomes of interest. The measles, mumps and rubella vaccine (MMR) given at one year of age, has obvious historical relevance since the measles epidemic of 1989-1990 constituted a major impetus for the development of the VFC program. In addition, however, it is given at an age at which poor and near-poor children in many states are transitioning from one level of eligibility for public health insurance assistance to another. It can, therefore, be instructive to contrast the income gradient for receipt of this vaccine with the income gradient for the Hepatitis B series that can be delivered before the first birthday.

The final vaccine that interested us was the varicella vaccine principally as a test of whether SCHIP influenced the rate of uptake of newly introduced vaccines. Licensed by the FDA in March of 1995, information on coverage in NIS was not available until 1997 (American Academy of Pediatrics 1995). It is, therefore, possible to trace the relative rate of uptake of this vaccine among poor and near-poor children compared with non-poor children as a function of SCHIP threshold levels.

\section{Regression specification}

SCHIP was established in 1997 although most state programs were not implemented until 1998 or later. Recall also that given the age of the children at survey, almost all began immunization between 1 to 2 years prior. Consequently, coverage rates in 1997 largely represent vaccinations in 1995 and 1996, prior to implementation of the SCHIP. Equation (1) below is a general representation of our reduced-form model. ${ }^{12}$

\footnotetext{
${ }^{12}$ For ease of presentation, we did not include unknown poverty and its interactions.
} 


$$
\begin{gathered}
Y_{i j t}=\beta_{0}+\beta_{1} \text { Poor }_{i j t}+\beta_{2} \text { Nearpoor }_{i j t}+\beta_{3} \text { SCHIP }_{i j t}+\beta_{4}\left(\text { Poor }_{i j t} * \text { SCHIP }_{i j t}\right)+ \\
\beta_{5}\left(\text { NearPoor }_{i j t} * S C H I P_{i j t}\right)+\mathbf{X} \boldsymbol{\alpha}+\sum_{j} \lambda_{j}+\sum_{t} \delta_{t}+e_{i j t}
\end{gathered}
$$

$\mathrm{Y}_{\mathrm{ijt}}$ is a dichotomous indicator of whether child $\mathrm{i}$, in state $\mathrm{j}$ and year $\mathrm{t}$ is up-to-date for a particular vaccine or up to date on a series; $Y_{\mathrm{ijt}}$ may also be an indicator of whether the child received the vaccine in a comprehensive care setting. Poor and Nearpoor are indicator variables of poverty status as described above. SCHIP in this specification is the average income eligibility threshold to which the child was exposed. Note that SCHIP varies by age, state and year. Moreover, with state fixed effects identification comes from within-state changes in eligibility thresholds. Finally, $\mathbf{X}$ is a matrix of maternal and child characteristics as well as the state unemployment rate and a measure of the Vaccine for Children program (VFC); ${ }^{13}$ and $\lambda_{\mathrm{j}}$ and $\delta_{\mathrm{t}}$ are state and year fixed effects, respectively. Summary statistics of selected characteristics by poverty status are presented in Table 2 of the Appendix.

The differential effect of SCHIP on poor and near-poor children is captured by the interaction terms. We expect $\beta_{4}$ and $\beta_{5}$ to be positive and as a first approximation we expect $\beta_{5}$ to exceed $\beta_{4}$ since many poor children would have been eligible for Medicaid prior to SCHIP. However, participation in Medicaid among poor children grew substantially between 1997 and

\footnotetext{
${ }^{13}$ The VFC is a federal entitlement that makes free vaccines available to children on Medicaid, uninsured, Native American or Alaskan Native and to underinsured children who obtain vaccines at federally qualified health centers. The VFC began enrollment in 1994. Provider participation rose rapidly and then leveled off in 1997. We include the number of VFC sites per children less than 19 years of age. The VFC is largely a supply-side intervention in which states purchase vaccines from the Centers for Disease Control and Prevention (CDC) and then distribute them to participating VFC providers. Although the VFC lowers the cost to providers of providing vaccinations to uninsured children, the VFC does not cover the cost of the visit nor the administration of the vaccine. Indeed, many physicians who participate in the VFC admitted that they would refer uninsured patients to the public health clinic for vaccinations (Zimmerman et al. 1997). SCHIP by contrast is a demand-side intervention that is awarded to parents and which covers the cost of the vaccine, its administration and the office visits.
} 
2001, despite few changes in eligibility thresholds. In an effort to enhance participation in SCHIP, many states expanded outreach. More importantly, states also streamlined enrollment procedures in both their SCHIP and regular Medicaid programs. Indeed, researchers recently reported that in 27 of the 38 states for which data were available, enrollment of children, families with children and pregnant women in "regular" Medicaid exceeded the number of children enrolled in SCHIP between 1997 and 2001 (Mann et al. 2002). Thus, we expect $\beta_{4}$ to be positive; it may even exceed $\beta_{5}$.

We use ordinary least squares to facilitate interpretation. None of the outcomes are in the extreme tails of the distribution and thus marginal effects from the linear and probit specifications are very similar. All regressions are weighted by the sampling probabilities and we use robust regression procedures to account for the fact that we have only state variation in our measures of program availability. ${ }^{14}$

\section{Results}

\section{Differences-in-Differences}

We present outcomes for the years before and after the implementation of SCHIP. We compare changes among poor and near-poor children to changes among the non-poor. These differences-in-differences (DDs) provide an initial assessment as to the possible association between SCHIP and vaccination rates and sites of care. Table 1 shows the proportion of children who obtained all vaccinations at one provider in 1996 and 2001, the years that largely bracket SCHIP. Note that we have two measures of this outcome. One is from the household survey and

\footnotetext{
${ }^{14}$ We used survey procedures in Stata 8.0 to adjust the standard errors for the sampling design in all bivariate comparisons. In the regressions, however, there is no way with the survey procedures to account for the aggregate form of our program measure. Thus, we use robust procedures that cluster on state.
} 
is based on parental recall. The other is from the provider survey. The comparison offers some insight into the sensitivity of the estimates from the two different sources. We also compare changes in whether all vaccines were obtained at one private provider, one public provider and at a provider that offered comprehensive pediatric services (private or public) in 1996 and 2001.

Substantial differences in vaccine sites between poor and non-poor in 1996 exist for those who obtained all vaccines at a private provider. Forty-six percent of the poor, 51 percent of the near-poor and 72 percent of the non-poor received all vaccines at a single private provider in 1996. These differences increase for the poor in 2001. As a result the DD for poor versus nonpoor are unexpectedly negative and statistically significant (DD1). The other notable result from Table 1 is that the proportion of poor children who saw only one provider or only one provider that offered comprehensive pediatric services also fell relative to the non-poor between 1996 and 2001. There was no similar deterioration among the near-poor, but we had expected the availability of insurance to increase the proportion of children who used only one provider, one private provider and a comprehensive care provider.

Vaccine coverage rates also differ by poverty in 1996. Poor and near-poor children are less likely to be up to date for the 4:3:1:3 series, hepatitis B and varicella. There are only modest differences for measles, mumps and rubella (MMR). However, except for varicella, there is little narrowing in these differences in 2001. The DDs are small in magnitude and statistically insignificant. The exception is varicella. In 1997, the first year for which data exist, 21 percent of poor, 23 percent of near-poor and 37 percent of non-poor children were vaccinated against chicken pox. By 2001 varicella coverage rates had increased dramatically: 77 percent, 76 percent, and 81 percent for poor, near-poor and non-poor respectively. The DDs for varicella are large and statistically significant, which is consistent with the extension of insurance to near-poor 
women. However, children from poor families experience the greatest gain in coverage rates in both absolute and relative terms. We expected that SCHIP would have had its most pronounced effect on near-poor children, but the increased enrollment in the Medicaid program may explain the results for poor children.

\section{Regression results}

The DDs provide an initial look at changes in our outcomes but they do not exploit variation in the timing or the extensiveness of SCHIP. To begin, we estimate equation (1) with dichotomous indicators for the year in which SCHIP was implemented and a one-year lag. We estimate a second set of regressions with the SCHIP variable represented by income eligibility threshold to which a child was exposed. Recall eligibility thresholds vary by state, year, age and vaccine. In the years prior to SCHIP we use the income eligibility thresholds for Medicaid children 0 to 5 years of age.

In Table 3, we display the coefficients on interaction between the dichotomous indicators for SCHIP and poverty from equation (1) for two vaccines and two vaccine series. There are four panels; each represents a different sample: Panel A includes all 50 states and Washington D.C. and is directly comparable to the DD estimates in Table 2; Panel B includes only the 28 urban Immunization Action Plan areas (IAPs); Panel C has the 17 states with highest rates of uninsured children and Panel D includes only Hispanics from the nine states with the largest Hispanic populations. The coefficients show the change in each vaccine or vaccine series among poor, near-poor and poverty unknown relative to non-poor children before and after implementation of SCHIP.

As with the DDs in Table 2, the strongest association between SCHIP and up-to-date status is found for varicella. Nationally, the probability that a poor or near-poor child was up to 
date for varicella increases between 7.0 and 7.4 percentage points more than among non-poor kids after SCHIP was implemented (Panel A). Importantly, these changes essentially double when we limit the sample to 28 IAPs, areas designated at risk for low immunization rates by the CDC (Panel B). Changes in varicella coverage rates are also greater in the 17 states with the highest rate of uninsured children (Panel C) and among Hispanics in the 9 states with largest Hispanic populations (Panel D). The same pattern exists among children for which poverty status is unknown. This is not surprising given that the education, marital status, race, and urban residence of mothers from household of unknown poverty are most similar to those of poor and near-poor families (see Table 2 of the Appendix).

Changes in the other vaccines are small and rarely of statistical significance in the national sample. The probability that a child is up to date for the 4:3:1:3 series increased 3.7 and 3.9 percentage points more among poor children and those of unknown poverty relative to non-poor children in states with high rates of uninsured children (Panel C). Near-poor Hispanic children also experience a relative gain of 6.4 percentage points for 4:3:1:3 and a 3.3 percentage point gain for Hepatitis B vaccine.

In Table 4 we show the same outcomes for the same samples but the coefficients represent the relative change associated with a 100 percentage-point increase in SCHIP income eligibility thresholds. The average change between 1995 and 2001 is approximately 70 percentage points. Several points are relevant. First, the results reveal a does-response effect between the magnitude of the change in eligibility thresholds and coverage rates for varicella. Specifically, a 100 percentage point increase in the income eligibility threshold is associated with a five percentage-point increase in the probability that a poor, near-poor or child of unknown poverty is up to date for varicella relative to a non-poor child across the U.S. (Panel A). The 
second point is that the more vulnerable the population, the larger the effect of a 100 percentage point increase. Finally, except for Hispanics and the 4:3:1:3 series (Panel D), there is no association between SCHIP eligibility thresholds and up-to-date status for the other vaccines.

We estimate the same regressions for the site of vaccine delivery but find little association or an association opposite to what we expected (results not shown). In short, they are few differences from the DDs in Table 1. For completeness, we show these results in Appendix Table 3.

A substantial portion of our sample lacks information on poverty: 24 percent in 1996 and 11.5 percent in 2001 . We have presented all results for children from families in which poverty is not known. Both the characteristics of these families and their association with SCHIP suggest that many are from poor or near-poor families. As an additional check, we create three groups of children based on maternal schooling and marital status, both of which are highly correlated with family income in our sample. Group 1 includes mothers who are not married and who have 12 years of schooling or less. Group 2 includes married women with 12 years of schooling or less and unmarried with 13 to 15 years of schooling. Group 3, the most advantaged, includes married women with at least a college degree. We then re-estimate the DDs in Table 2 and contrast Group 1 and Group 2 to Group 3. The results are remarkably similar to those obtained using poor and near-poor children (available upon request).

To summarize, we find that SCHIP is consistently associated with relative increases in varicella vaccine in both the simple DD and in the adjusted regression models. There are modest and less consistent increases in Hepatitis B and in the 4:3:1:3 series among various subgroups. In addition, increases are greater among groups at greater risk for lacking insurance or under immunization. To further examine the link between increased varicella coverage rates 
and SCHIP, we divide states by the year they implemented their SCHIP program: eight states in 1997, 33 in 1998 and eight in 1999 and two in 2000. We then run separate regressions of whether a child is up to date with respect to the varicella vaccine for each group of states (we combine 1999 and 2000). However, instead of including an explicit measure of SCHIP, we interact the time dummies with indicators of poor, near-poor and children of unknown poverty. If SCHIP is responsible for the increase in varicella coverage rates, then we would expect to see relatively greater increases in varicella coverage rates in 1998 among near-poor kids from states that implemented SCHIP in 1997 than among kids from states that implemented SCHIP in 1999. In Figures 2 and 3 we plot the coefficients from the year/poor and year/near-poor interactions. Each point shows the change in varicella coverage rates between 1997 and each subsequent year relative to the change among non-poor children. Thus, between 1997 and 1998, varicella coverage rates increase approximately 18 percentages points more among poor relative to nonpoor children in states that implemented their SCHIP programs in 1997 (Figure 2). However, there was a relative increase of 12 percentage-points between 1997 and 1998 among poor children in states whose SCHIP programs did not begin until 1998 or later. The results in Figure 3 are also less than convincing as to a casual relationship between SCHIP and the uptake of varicella vaccine. The largest increase between 1997 and 1998 is among near-poor children in states whose SCHIP programs did not begin until 1999.

\section{Sample Selection}

As noted in Table 1 of the Appendix, respondents in the household survey for whom provider data were not available differ from respondents with provider data along several observable characteristics. The Centers for Disease Control and Prevention publishes annual vaccination rates based on the data obtained from the provider survey only, since these are 
considered the most reliable. In order to minimize the loss of data, we included, whenever possible, all respondents with provider data along with all respondents who used a shot card to recall vaccines. Respondents with only a shot card tend to be poorer, less educated and more likely to be Hispanic than respondents with neither a shot card nor provider data (Appendix Table 1).

We check for the possibility of sample selection bias in several ways. First, we re-run the basic regressions and limit the sample to children for whom only provider data are available. Our findings are not substantively altered. In addition, in the household survey, respondents are asked how many vaccination providers they use. We include as an outcome whether the respondent used only one provider for all vaccinations. We compare results for this self-reported measure of provider use to results for the same outcome but based on data collected exclusively from providers. A review of the DD estimates in Table 1 reveals no differences. Finally, we estimate a bivariate probit that allows for a cross-equation correlation. The first equation is whether provider data are available for the respondent. The second equation is whether the child is up to date for varicella. To improve identification, we exclude from the second stage an indicator of whether the child's state of residence at the time of the survey is different from the child's state of birth. We assume the reasons for moving are unrelated to a child's vaccinations. However, parents who move are much more likely to have more than one provider, which lessens the likelihood of being in the provider survey. In our sample, for instance, 58 percent of the children who are born in states different from where they reside at the time of the survey obtain vaccines at more than one provider as compared to 29 percent who reside in the same state in which they were born. ${ }^{15}$

\footnotetext{
${ }^{15}$ The number of providers a child saw for vaccines is based on the household survey and not the provider survey.
} 
In results not shown, we obtained a cross-equation correlation of 0.12 from estimation of the bivariate probit $(\mathrm{p}<0.01)$. The positive correlation is expected: children more likely to be in the provider survey are more likely to be up to date for varicella vaccine. However, the marginal effects of SCHIP in the varicella equation obtained from the bivariate probit are no different from those that we obtain when we restrict the cross-equation correlation to be zero. In sum, we do not believe that merging the two sources of information on vaccine coverage alters our results in any meaningful manner.

\section{Conclusion}

There has been an unprecedented extension of publicly financed health insurance to poor and near-poor children since the mid 1980s. SCHIP is the most recent example. Numerous studies have linked increases in the availability of health insurance to increases in health care utilization among children. However, measures of utilization are often too general to infer much about the quality of care or its effect on health. In this study, we associated changes in SCHIP with changes in immunization coverage rates and the site at which vaccines are received. Vaccines are arguably the greatest public health achievement of the $20^{\text {th }}$ century, and a highly effective measure of both the quality of pediatric care as well as the improvement in health associated with vaccine preventable illnesses.

We found little evidence to suggest that SCHIP has had a major impact on narrowing the immunization coverage rate gaps among poor and near-poor children relative to their non-poor counterparts. The one exception is the varicella vaccine in which differences in coverage rates between poor, near-poor and non-poor children converged rapidly between 1996 and 2001. Moreover, convergence was faster among poor and near-poor children from groups or areas with 
above average rates of uninsured children. Unfortunately, improvements in varicella coverage cannot be tightly linked to the timing of SCHIP program implementation and thus, we caution against a causal interpretation. The association, however, is a potentially important finding if it suggests that health insurance plays a substantive role in the uptake of new vaccines. The pneumococcal conjugate recommended for all children in 2001, not only protects against the most common cause of bacterial meningitis, but also lowers the incidence of acute otitis media, a common childhood illness (Eskola et al. 2001). The pneumococcal vaccine, however, is costly. At approximately $\$ 200$ for a series of four doses, it is twice as expensive as the varicella vaccine. The availability of insurance may be a significant determinant of its uptake among poor and near-poor children.

Our results for the varicella vaccine point to substantial "spillover" effects associated with SCHIP. We generally found greater convergence in coverage rates among poor children even though most were likely eligible for publicly provided insurance before SCHIP. If the outreach efforts and the simplification of enrollment procedures are responsible for the uptake among Medicaid-eligible children, and if such reforms would not have occurred without SCHIP, then in a reduced-form sense, the results for poor and near-poor children are a consequence of the SCHIP initiative.

The other unexpected result was the decline in the proportion of children who received vaccines at a single provider or a single private provider. We had anticipated that SCHIP would increase the proportion of near-poor children within "medical homes." It may be that the complexity of the immunization schedule combined with the expense associated with fully vaccinating a child, and the large number of near-poor children who cycle in and out of different insurance plans during the course of a given year encouraged many parents to obtain vaccines 
in both the private and public sector, in a kind of "catch as catch can" approach to immunizations. This is not a welcome result. Multiple sites complicate record keeping, confound reminder systems, and lessen the opportunities for pediatric screening, particularly if vaccines are obtained in public health clinics that do not provide comprehensive services. In sum, it appears that great strides have been made at improving age-appropriate coverage rates among poor and near-poor children since the measles epidemic in 1990. The challenge going forward will be to devise both supply and demand side mechanisms that encourage parents to establish a "medical home" for pediatric care. 


\section{Acknowledgments}

This research was made possible by a grant from the Robert Wood Johnson Foundation Changes in Health Care Financing Organization (HCFO) Initiative to the Baruch College Fund. We thank Silvie Colman for expert research assistance and Lisa Dubay from the Urban Institute for Information on SCHIP. An initial version of this paper was presented at the 14 Annual Health Economics Conference at RAND in Santa Monica, CA in April, 2003. We thank Bob Schoeni and other participants for their comments. 


\section{References}

American Academy of Pediatrics, Committee on Infectious Diseases (1995). "Recommendations for the use of live attenuated varicella vaccine.” Pediatrics 1995; 95: 791-796.

Centers for Disease Control and Prevention (1992). "Public Sector Vaccination Efforts in Response to the Resurgence of Measles Among Preschool-Aged Children-United States 19891991." MMWR. 41:522-525.

Centers for Disease Control and Prevention (1991). "Hepatitis B Virus: A Comprehensive Strategy for Eliminating Transmission in the United States through Universal Childhood Vaccination: Recommendations of the Immunization Practices Advisory Committee (ACIP)." MMWR. 40(RR-13): 1-19.

Centers for Disease Control and Prevention (1992). "Report Vaccine-Preventable DiseasesUnited States 1993, and the Childhood Immunization Initiative.” MMWR. 43:57-60.

Center for Disease Control and Prevention (2002). "General Recommendations on Immunization: Recommendations of the Advisory Committee on Immunization Practices (ACIP) and the American Academy of Family Physicians (AAFP).” MMWR 51:1-36.

Center for Disease Control and Prevention (2003). "Notice to Readers." MMWR 52(10): 11-12.

Congressional Budget Office (2003). "How Many People Lack Health Insurance and For How Long."

Currie, J., Gruber J. (1996). "Health Insurance Eligibility, Utilization of Medical Care, and Child Health" The Quarterly Journal of Economics 431-466.

Dubay, L., Hill, I. and Kenney, G. (2002). "Five Things Everyone Should Know about SCHIP." The Urban Institute Series A, No. A-55.

Dubay, L. and G. M. Kenney (2001). "Health care access and use among low-income children: who fares best?" Health Aff (Millwood) 20(1): 112-21.

Dubay, L., Kenney, G. and Haley J. (2002). "Children's Participation in Medicaid and SCHIP: Early in the SCHIP Era." The Urban Institute, Series B, No. B-40.

Eskola, J. et al. (2001). "Efficacy of a Pneumococcal Conjugate Vaccine against Acute Otitis Media."New England Journal of Medicine 344(6): 403-409.

Fierman. A.H. et al. (1996). "Immunization Status as Determined by Patients' hand-held cards vs. medical records." Archives of Pediatrics and Adolescent Medicine 150(8): 863.

Institute of Medicine (2000). "Calling the Shots: Immunization Finance Policies and Practices." Committee on Immunization Finance Policies and Practices, Division of Health Care Services 
and Division of Health Promotion and Disease Prevention. Washington, DC: National Academy Press.

Kaestner, R., Joyce, T., and A. Racine. (2001). "Medicaid Eligibility and the Incidence of Ambulatory Care Sensitive Hospitalizations for Children.” Social Science and Medicine. 52: 305-313.

Kenney, G., L. Dubay and J. Haley (2000). "Health Insurance, Access, and Health Status of Children” Snapshots of America’s Families II. The Urban Institute, Washington, D.C.

Kerpelman, L., Connell, D. and W.Gunn (2000). "Effect of a Monetary Sanction on Immunization Rates of Recipients of Aid to Families with Dependent Children." JAMA 284(1): 53-59.

Lave, J.R. et al. (1998). "Impact of a Children's Health Insurance Program on Newly Enrolled Children.” JAMA 279(22): 1820-1825.

Levy, H. and Meltzer, D. (2001). "What Do We Really Know About Whether Health Insurance Affects Health?” Unpublished manuscript.

LoSasso, A.T. and Buchmueller, T.C. (2002). "The Effect of the State Children's Health Insurance Program on Health Insurance Coverage.” NBER Working Paper 9405.

Lurie, N. et al. (1987). “Preventive Care: Do We Practice What We Preach?” AJHPH 77(7): 801-804.

Lykens, K.A and Jargowsky, P.A. (2002). “Medicaid Matters: Children's Health and Medicaid Eligibility Expansions." Journal of Policy Analysis and Management 21(2).

Mann, C. et al. (2002). "Reaching Uninsured Children through Medicaid: If You Build It Right, They will Come.” Kaiser Commission on Medicaid and the Uninsured.

Mustin, H.D., Holt, V.L. and Connell, F.A. (1994). “Adequacy of Well-Child Care and Immunizations in US Infants Born in 1988.” JAMA 272(14): 1111-1115.

National Vaccine Advisory Committee (NVAC) (1991). "The Measles Epidemic. The Problems, Barriers, and Recommendations.” JAMA 266(11): 1547-1552.

National Vaccine Advisory Committee (NVAC) (1999). "Strategies to Sustain Success in Childhood Immunizations." JAMA 282(4): 363-370.

Newacheck, P. et al. (1998a). "Health Insurance and Access to Primary Care for Children." The New England Journal of Medicine 338(8): 513-519.

Newacheck, P. et al. (1998b). "The Role of Medicaid in Ensuring Children's Access to Care." JAMA 280(20): 1789-1115. 
Newhouse, J. et al. (1993). Free for All: Lessons from the RAND Health Insurance Experiment. Cambridge, MA: Harvard University Press.

Pernice, C. et al. (2001). Charting SCHIP: Report of the Second National Survey of the State Children's Health Insurance Program. Portland, ME: National Academy for State Health Policy.

Racine, A.D., Kaestner, R., Joyce, T.J., and Colman, G.J. (2001). “Differential Impact of Recent Medicaid Expansions by Race and Ethnicity." Pediatrics 108(5): 1135-1142.

Rodewald, L. et al. (1997). "Health Insurance for Low-Income Working Families: Effect on the Provision of Immunizations to Preschool-Age Children." Archives of Pediatric Adolescent Medicine. 151(August):798-803.

Rosenbach, M. et al. (2001). "Implementation of the State Children's Health Insurance Program: Momentum Is Increasing After a Modest Start (First Annual Report).” Cambridge, MA:

Mathematica Policy Research, Inc.

Smith, P.J. et al. (2001). "Overview of the Sampling Design and Statistical Methods Used in the National Immunization Survey." American Journal of Preventive Medicine 20(4S): 17-24.

Suarez, L., Simpson, D.M. and Smith, D.R. (1997). "Errors and Correlates in Parental Recall of Child Immunizations: Effects on Vaccination Coverage Estimates.” Pediatrics 99(5).

Szilagyi, et al. (2000a). "Evaluation of a State Health Insurance Program for Low-Income Children: Implications for State Child Health Insurance Programs.” Pediatrics 105(2): 363-371.

Szilagyi, et al. (2000b). "Evaluation of New York State's Health Plus: Children Who Have Asthma." Pediatrics 105(3): 719-727.

Szilagyi, P. G., J. L. Holl, et al. (2000). "Evaluation of New York State's Child Health Plus: children who have asthma." Pediatrics 105(3 Suppl E): 719-27.

Zimmerman, et al. (1997). "Impact of Free Vaccine and Insurance Status on Physician Referral of Children to Public Vaccine Clinics.” JAMA 278(12): 996-1000.

Zimmerman, et al. (2001). "Effect of the Vaccines for Children Program on Physician Referral of Children to Public Vaccine Clinics: A Pre-Post Comparison." Pediatrics 108(2): 297-304. 


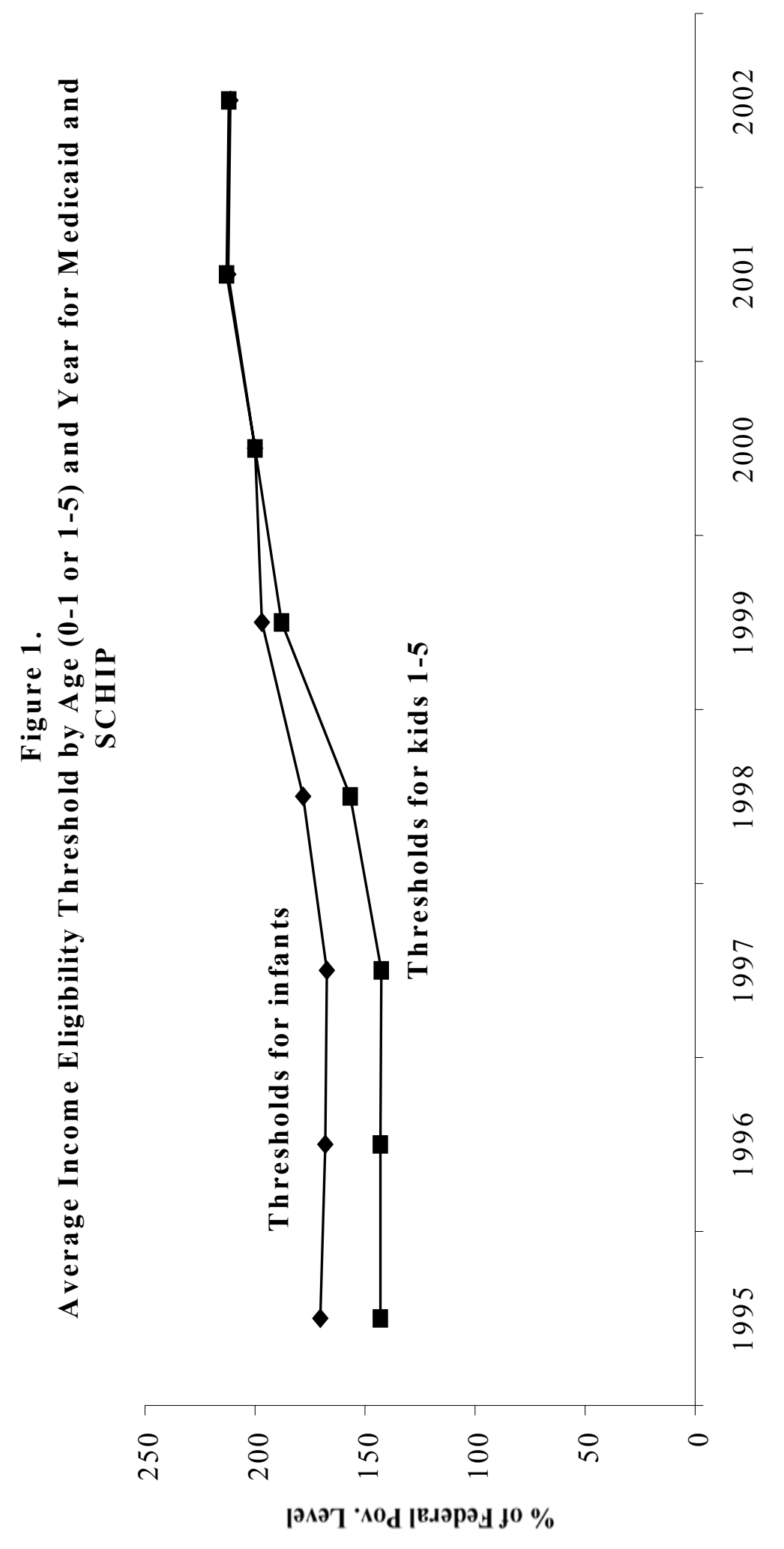




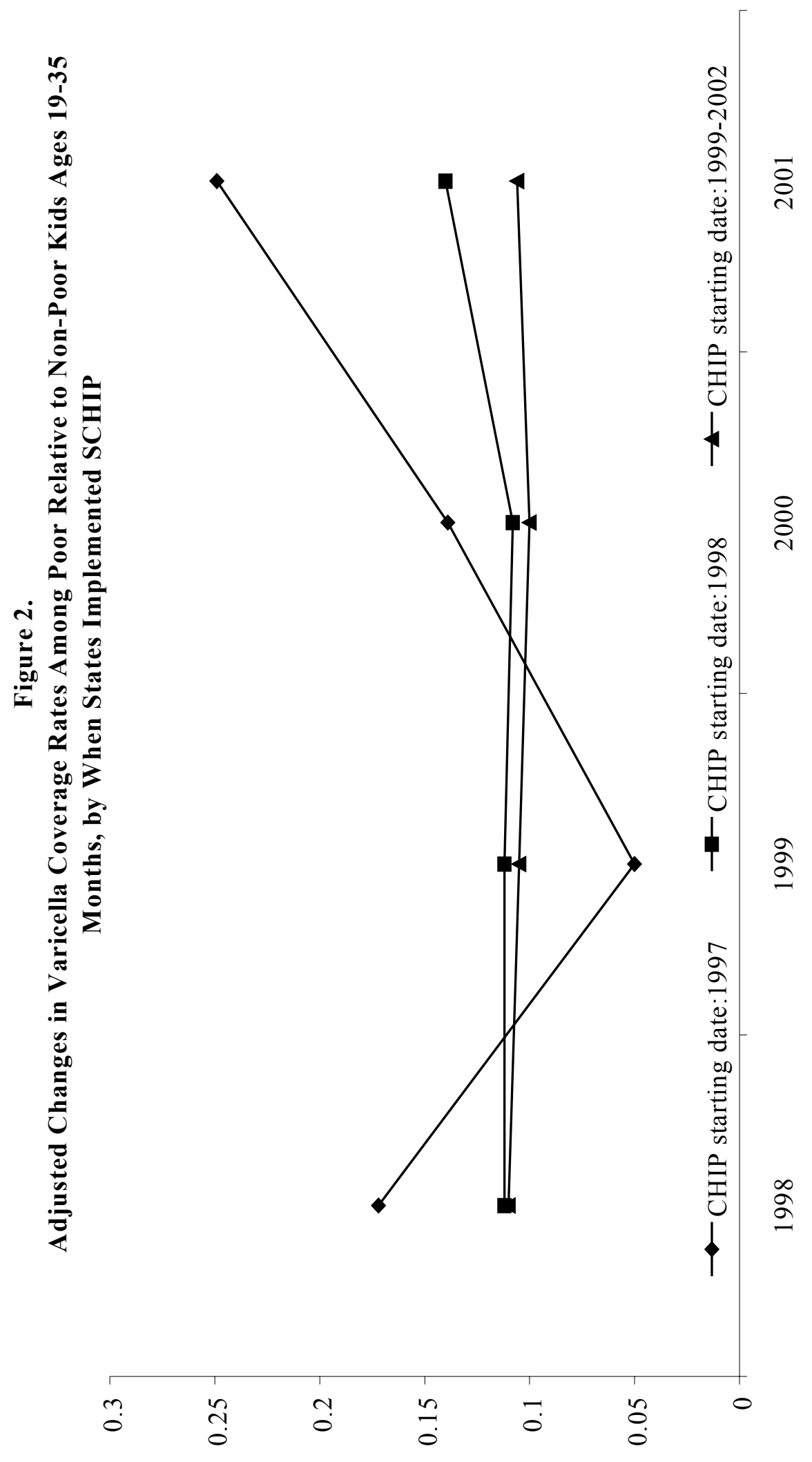




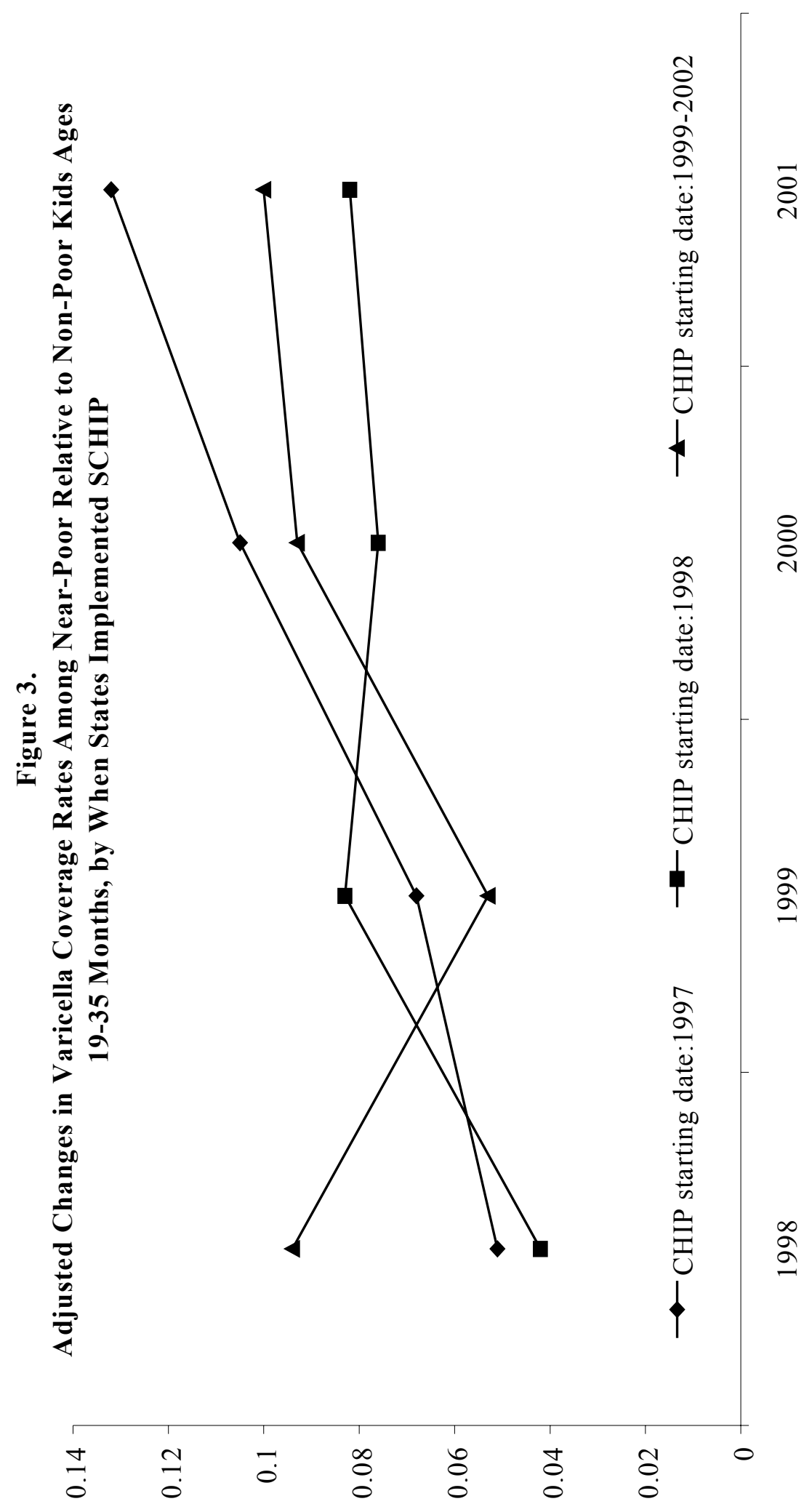


Table 1.

Proportion of Vaccines Obtained by Characteristics of the Provider, Poverty Status and Year: 1996 and 2001

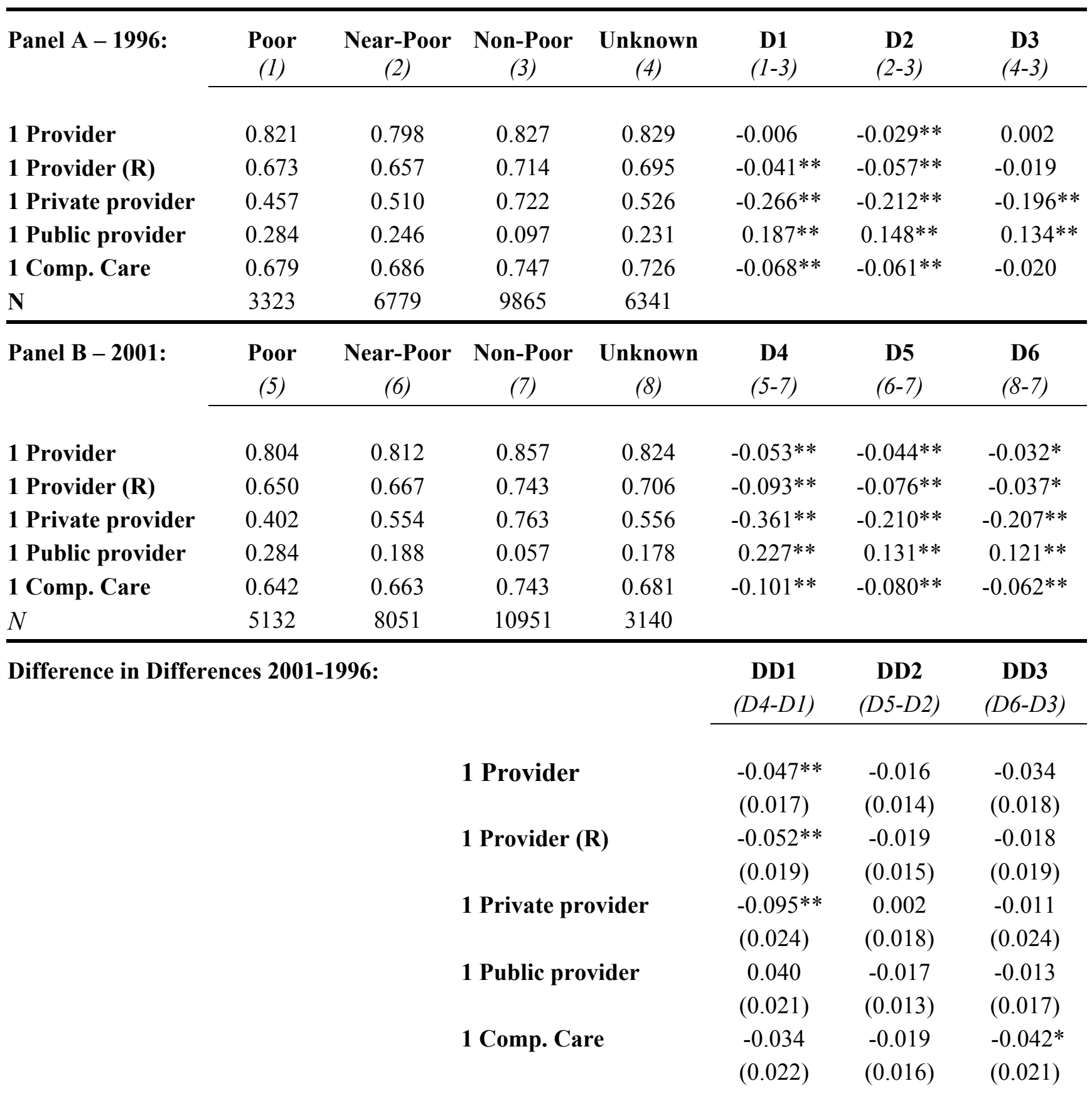

* significant at 5\%;** significant at 1\%. The outcomes refer to children who obtain all vaccines at one Provider, one Private Provider, one Public Provider and one Provider that offers comprehensive pediatric services as record by the provider survey or at one Provider (R) as recorded by the household survey. Columns headed by a "D" represent first differences and those headed by "DD" are difference-in-differences. Standard errors adjusted for the survey design are in parentheses. 
Table 2.

Proportion of Children 19 to 35 Months of Age Up to Date (UTD) for Vaccine Series (4:3:1:3) and Selected Other Vaccines by Poverty Status and Year: 1996 and 2001

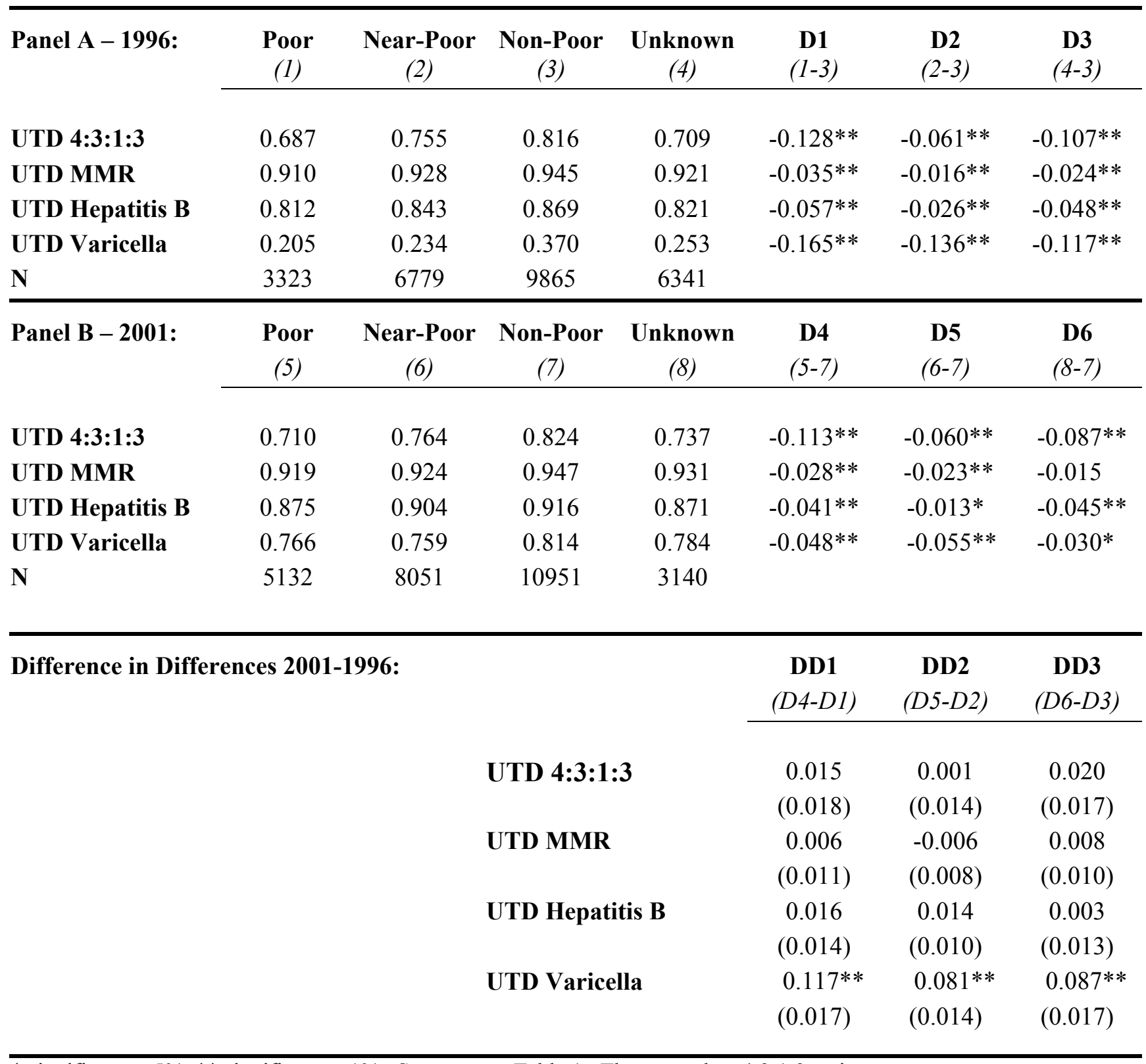

* significant at 5\%;* significant at 1\%. See notes to Table 1 . The up-to-date 4:3:1:3 series represents four diphtheria, tetanus and acellular pertussis vaccines (DtaP), three polio vaccines, one measles containing vaccine, and three Haemophilus influenza vaccines by eighteen months of age. 
Table 3.

Regression Estimates of the Association between the Up to Date Status of Vaccines and the Implementation of the State Children's Health Insurance Program (SCHIP) for Children 19 to 35 Months by Poverty Status for Entire U.S. and Selected Sub-groups, 1995-2001 ${ }^{+}$

\begin{tabular}{|c|c|c|c|c|}
\hline & UTD $4: 3: 1: 3$ & UTD Hepatitis B & UTD MMR & UTD Varicella \\
\hline & \multicolumn{4}{|c|}{ Panel A: National estimates } \\
\hline \multirow[t]{2}{*}{ 1.poor - non-poor } & 0.012 & 0.006 & $0.016^{*}$ & $0.070 * *$ \\
\hline & $(0.018)$ & $(0.015)$ & $(0.008)$ & $(0.023)$ \\
\hline \multirow[t]{2}{*}{ 2.near-poor - non-poor } & 0.012 & $0.014 *$ & 0.004 & $0.074 * *$ \\
\hline & $(0.011)$ & $(0.007)$ & $(0.005)$ & $(0.012)$ \\
\hline \multirow[t]{2}{*}{ 3.pooruk - non-poor } & 0.022 & 0.004 & 0.010 & $0.051 * *$ \\
\hline & $(0.013)$ & $(0.006)$ & $(0.006)$ & $(0.019)$ \\
\hline $\mathbf{N}$ & 183973 & 183973 & 184115 & 134416 \\
\hline \multirow[t]{2}{*}{ R-squared } & 0.094 & 0.072 & 0.019 & 0.182 \\
\hline & \multicolumn{4}{|c|}{ Panel B: 28 Urban Immunization Action Plan areas only: } \\
\hline \multirow[t]{2}{*}{ 1.poor - non-poor } & -0.005 & 0.020 & 0.027 & $0.157 * *$ \\
\hline & $(0.026)$ & $(0.023)$ & $(0.014)$ & $(0.037)$ \\
\hline \multirow[t]{2}{*}{ 2.near-poor - non-poor } & -0.001 & 0.003 & 0.022 & $0.147 * *$ \\
\hline & $(0.022)$ & $(0.012)$ & $(0.012)$ & $(0.039)$ \\
\hline \multirow[t]{2}{*}{ 3.pooruk - non-poor } & 0.017 & 0.017 & 0.016 & $0.121 * *$ \\
\hline & $(0.024)$ & $(0.017)$ & $(0.010)$ & $(0.039)$ \\
\hline $\mathbf{N}$ & 63790 & 63790 & 63831 & 47211 \\
\hline \multirow[t]{2}{*}{ R-squared } & 0.113 & 0.070 & 0.020 & 0.197 \\
\hline & \multicolumn{4}{|c|}{ Panel C: 17 states with the highest rate of uninsured kids in 1995-1997 } \\
\hline \multirow[t]{2}{*}{ 1.poor - non-poor } & $0.037 *$ & 0.007 & $0.023 * *$ & $0.105 * *$ \\
\hline & $(0.016)$ & $(0.024)$ & $(0.009)$ & $(0.038)$ \\
\hline \multirow[t]{2}{*}{ 2.near-poor - non-poor } & 0.026 & 0.009 & -0.001 & $0.099 * *$ \\
\hline & $(0.016)$ & $(0.008)$ & $(0.008)$ & $(0.018)$ \\
\hline \multirow[t]{2}{*}{ 3.pooruk - non-poor } & $0.039 *$ & 0.000 & 0.002 & $0.077^{*}$ \\
\hline & $(0.019)$ & $(0.009)$ & $(0.007)$ & $(0.036)$ \\
\hline $\mathbf{N}$ & 71950 & 71950 & 72001 & 53124 \\
\hline R-squared & 0.089 & 0.066 & 0.016 & 0.192 \\
\hline
\end{tabular}


Table 3. Continued:

\begin{tabular}{lcccc}
\hline & UTD 4:3:1:3 & UTD Hepatitis B & UTD MMR & UTD Varicella \\
\hline & \multicolumn{2}{c}{ Panel D: Hispanics only, in 9 states with large Hispanic population } \\
1.poor - non-poor & 0.031 & 0.013 & $-0.023^{*}$ & $0.138^{* *}$ \\
& $(0.037)$ & $(0.031)$ & $(0.010)$ & $(0.043)$ \\
2.near-poor - non-poor & $0.064 * *$ & $0.033^{*}$ & -0.023 & $0.120^{* *}$ \\
& $(0.021)$ & $(0.017)$ & $(0.018)$ & $(0.036)$ \\
3.pooruk - non-poor & $0.062^{*}$ & 0.025 & -0.029 & $0.120^{* *}$ \\
N & $(0.029)$ & $(0.021)$ & $(0.018)$ & $(0.042)$ \\
R-squared & 20188 & 20188 & 20194 & 15412 \\
& 0.111 & 0.085 & 0.018 & 0.217 \\
\hline
\end{tabular}

* significant at 5\%; ** significant at 1\%. Estimates obtained by ordinary least squares. Robust standard errors have been adjusted for clustering at the state or IAP level. All models include state (or IAP) and year fixed effects. Figures show the differential change in the probability of each outcome as shown in equation (1). The 28 IAPs include MA-City of Boston, NJ-City of Newark, NY-NYC 5 Counties, District of Columbia, MD-City of Baltimore, PA-Philadelphia County, AL-Jefferson County, FL-Duval County, FL-Dade County, GA-Fulton/Dekalb Counties, TN-Shelby County, TN-Davidson County, ILl-City of Chicago, IN-Marion County, MI-City of Detroit, OHCuyahoga County, OH-Franklin County, WI-Milwaukee County, LA-Orleans Parish, TX-Dallas County, TX-El Paso County, TX-City of Houston, TX-Bexar County, AZ-Maricopa County, CA-Los Angeles County, CA-Santa Clara County, CA-San Diego County, WA-King County. The 17 states with the highest rate of uninsured children between 1995-1997 include Arizona, Arkansas, California, Colorado, District of Columbia, Florida, Georgia, Idaho, Louisiana, Mississippi, Nevada, New Jersey, New Mexico, North Carolina, Oklahoma, South Carolina, Texas. The 9 states with largest Hispanic population are: Arizona, California, Florida, Illinois, Massachusetts, New Jersey, New Mexico, New York, Texas. 
Table 4.

Regression Estimates of the Association between the Up to Date Status of Vaccines and Income Eligibility Thresholds for the State Children's Health Insurance Program (SCHIP) for Children 19 to 35 Months by Poverty Status for Entire U.S. and Selected Sub-groups, 1995-2001 ${ }^{+}$

\begin{tabular}{|c|c|c|c|c|}
\hline & UTD $4: 3: 1: 3$ & UTD Hepatitis B & UTD MMR & UTD Varicella \\
\hline & \multicolumn{4}{|c|}{ Panel A: National estimates } \\
\hline \multirow[t]{2}{*}{ 1.poor - non-poor } & 0.026 & -0.001 & 0.008 & $0.051 *$ \\
\hline & $(0.017)$ & $(0.015)$ & $(0.009)$ & $(0.025)$ \\
\hline \multirow[t]{2}{*}{ 2.near-poor - non-poor } & 0.017 & 0.021 & -0.004 & $0.052 * *$ \\
\hline & $(0.015)$ & $(0.013)$ & $(0.007)$ & $(0.018)$ \\
\hline \multirow[t]{2}{*}{ 3.pooruk - non-poor } & 0.026 & 0.004 & 0.003 & $0.054 * *$ \\
\hline & $(0.020)$ & $(0.010)$ & $(0.006)$ & $(0.011)$ \\
\hline $\mathbf{N}$ & 183973 & 183973 & 184115 & 134416 \\
\hline \multirow[t]{2}{*}{ R-squared } & 0.094 & 0.072 & 0.019 & 0.182 \\
\hline & \multicolumn{4}{|c|}{ Panel B: 28 Urban Immunization Action Plan areas only: } \\
\hline \multirow[t]{2}{*}{ 1.poor - non-poor } & 0.006 & 0.002 & 0.027 & $0.092 *$ \\
\hline & $(0.021)$ & $(0.023)$ & $(0.022)$ & $(0.040)$ \\
\hline \multirow[t]{2}{*}{ 2.near-poor - non-poor } & -0.012 & 0.014 & 0.018 & 0.060 \\
\hline & $(0.037)$ & $(0.024)$ & $(0.025)$ & $(0.057)$ \\
\hline \multirow[t]{2}{*}{ 3.pooruk - non-poor } & 0.024 & 0.027 & 0.025 & $0.105 * *$ \\
\hline & $(0.053)$ & $(0.030)$ & $(0.018)$ & $(0.031)$ \\
\hline $\mathbf{N}$ & 63790 & 63790 & 63831 & 47211 \\
\hline \multirow[t]{2}{*}{ R-squared } & 0.113 & 0.069 & 0.020 & 0.196 \\
\hline & \multicolumn{4}{|c|}{ Panel C: 17 states with the highest rate of uninsured kids in 1995-1997 } \\
\hline \multirow[t]{2}{*}{ 1.poor - non-poor } & 0.035 & 0.000 & 0.014 & $0.089 * *$ \\
\hline & $(0.034)$ & $(0.025)$ & $(0.017)$ & $(0.029)$ \\
\hline \multirow[t]{2}{*}{ 2.near-poor - non-poor } & 0.031 & 0.027 & -0.013 & $0.077 * *$ \\
\hline & $(0.033)$ & $(0.014))$ & $(0.014)$ & $(0.016)$ \\
\hline \multirow[t]{2}{*}{ 3.pooruk - non-poor } & 0.053 & 0.008 & 0.000 & $0.063 * *$ \\
\hline & $(0.045)$ & $(0.011)$ & $(0.008)$ & $(0.022)$ \\
\hline $\mathbf{N}$ & 71950 & 71950 & 72001 & 53124 \\
\hline R-squared & 0.088 & 0.066 & 0.015 & 0.191 \\
\hline
\end{tabular}


Table 4. Continued:

\begin{tabular}{lcccc}
\hline & UTD 4:3:1:3 & UTD Hepatitis B & UTD MMR & UTD Varicella \\
\hline & \multicolumn{2}{c}{ Panel D: Hispanics only, in 9 states } & with large Hispanic population \\
1.poor - non-poor & $0.054^{* *}$ & 0.036 & -0.016 & $0.091^{*}$ \\
2.near-poor - non-poor & $(0.014)$ & $(0.042)$ & $(0.013)$ & $(0.040)$ \\
& $0.079^{* *}$ & 0.057 & -0.007 & 0.047 \\
3.pooruk - non-poor & $(0.017)$ & $(0.037)$ & $(0.020)$ & $(0.034)$ \\
& $0.105^{* *}$ & 0.059 & -0.024 & $0.084^{* *}$ \\
N & $(0.023)$ & $(0.045)$ & $(0.016)$ & $(0.031)$ \\
R-squared & 20188 & 20188 & 20194 & 15412 \\
& 0.110 & 0.085 & 0.017 & 0.215 \\
\hline
\end{tabular}

* significant at 5\%; ** significant at $1 \%$. See notes to Table 3 . 
Appendix Table 1.

Source of Immunization Information by Characteristics of the Child/Family, National Immunization Survey 1995-2001

\begin{tabular}{ccccccc} 
Total & $\begin{array}{c}\text { Shot Card } \\
\text { Alone }\end{array}$ & $\begin{array}{c}\text { Provider } \\
\text { Alone }\end{array}$ & $\begin{array}{c}\text { Shot Card } \\
\text { and } \\
\text { Provider }\end{array}$ & $\begin{array}{c}\text { Neither } \\
\text { Shot Card } \\
\text { nor } \\
\text { Provider } \\
(5)\end{array}$ & $\begin{array}{c}\text { Total vs. } \\
\text { Shot Card } \\
\text { or Provider }\end{array}$ & $\begin{array}{c}\text { Total v } \\
\text { Provid }\end{array}$ \\
& $(1)$ vs. (2-4)) & $(1$ vs. $)$ \\
\hline & & $(3)$ & $(4)$ & & & \\
0.297 & 0.303 & 0.294 & 0.301 & 0.292 & -0.002 & 0.003 \\
0.351 & 0.346 & 0.353 & 0.354 & 0.349 & -0.001 & -0.002 \\
0.351 & 0.351 & 0.353 & 0.345 & 0.359 & 0.002 & -0.002
\end{tabular}

Child's Age:

19-23 months

24-29 months

30-35 months

0.351

0.614

0.529

0.673

0.617

0.588

$-0.059 * *$

Black Non-Hisp.

0.150

0.144

0.158

0.107

0.210

$0.017 * *$

$-0.008 * *$

Hispanic

0.186

0.126

0.225

0.150

$-0.010 * *$

$0.060 * *$

Other

0.050

0.059

0.043

0.051

0.051

0.000

$0.007 * *$

Number of Children:

1

2-3

4 or more

Unknown
0.285

0.589

0.285

0.580

0.123

0.131

0.003

0.004

0.275

0.607

0.116

0.001

0.288

0.594

0.116

0.001

0.003

0.198

0.004

0.165

0.206

0.257

0.282

0.382

13-15 years

$\geq 16$ years

\section{Poverty Status:}

Poor

Near-Poor

0.171

0.270

0.185

0.334

0.254

0.289

0.226

0.517

Male

Mobility

0.511

0.141

0.290

0.217

32,787

N
0.707

0.098

0.194

0.001

0.133

0.395

0.177

0.295

0.161

0.282

0.381

0.175

0.512

0.070

0.173

0.751

0.078

0.170

0.001

0.183

0.367

0.162

0.287

0.185

0.289

0.344

0.182

0.508

0.083

0.216

71,012

79,913
0.293

0.563

0.136

0.008

0.660

0.106

0.226

0.008

0.002

$0.010 * *$

$-0.007 * *$

$-0.018^{* *}$

$0.004 *$

$0.006^{* *}$

$0.001 * *$

$0.002 * *$

$\begin{array}{lll}0.150 & -0.004 * & 0.032 * * \\ 0.412 & 0.007 * * & -0.008 * \\ 0.165 & 0.000 & -0.011^{* *} \\ 0.273 & -0.003 & -0.014 * *\end{array}$

$\begin{array}{lll}0.151 & -0.005^{* *} & 0.009^{* *} \\ 0.234 & -0.010^{* *} & -0.012^{* *} \\ 0.296 & -0.010^{* *} & -0.048^{* *} \\ 0.320 & 0.026 * * & 0.050^{* *} \\ 0.513 & 0.000 & -0.001 \\ 0.127 & 0.008^{* *} & 0.028^{* *} \\ 0.229 & 0.003 * * & 0.044^{* *}\end{array}$

$-0.015^{* *} \quad 0.006^{*}$

$0.004 * * \quad-0.007 * *$

$0.009 * * \quad-0.001$

$0.001 * * \quad 0.002 * *$

$0.044 * *$

* significant at $5 \% ; * *$ significant at $1 \%$ 
Appendix Table 2.

Characteristics of Mother and Child by Poverty Status, National Immunization Survey, 1995-2001.

Child's Age:

Poor Near

24-29 months

0.303

0.294

0.295

0.300

0.351

0.349

0.353

0.351

30-35 months

0.345

0.357

0.351

0.350

\section{Mother's Race:}

White Non-Hisp.

0.353

0.648

0.804

0.490

Black Non-Hisp.

0.258

0.139

0.078

0.186

Hispanic

0.341

0.169

0.070

0.263

Other

0.048

0.044

0.048

0.061

\section{Number of Children:}

\section{1}

2-3

4 or more

Unknown
0.233

0.558

0.209

0.000
0.269

0.615

0.116

0.000

0.744

0.089

0.167

0.000

0.446

0.162

0.392

0.000

Unknown

\section{Mother's Education:}

$<12$ years

12 years

13-15 years

$\geq 16$ years

Male

Mobility

Live in Urban Area

$\mathrm{N}$
0.354

0.459

0.118

0.069

0.507

0.100

0.288

36878
0.125

0.485

0.207

0.183

0.512

0.088

0.183

64114
0.358

0.593

0.049

0.000

0.235

0.578

0.173

0.014

Footnote: Poor is defined as family income $<100 \%$ Federal poverty level; Near-poor $100-<250 \%$ FPL, Nonpoor $>=250 \%$ FPL. Mobility means the child's state of residence at the interview differed from his/her state of birth. Urban areas represent 28 Immunization Action Plan areas (IAPs) designated by the CDC. See the note to Table 3 in the text for a list of the IAPs. 
Appendix Table 3.

Regression Estimates of the Association between the Probability that a Child Obtained All Vaccines at a Type of Provider and the Implementation of the State Children's Health Insurance Program (SCHIP) for Children 19 to 35 Months by Poverty Status for Entire U.S. and Selected Sub-groups, 1995-2001 ${ }^{+}$

\begin{tabular}{|c|c|c|c|c|c|}
\hline & 1 Provider (R) & 1 Provider & $\begin{array}{l}1 \text { Private } \\
\text { Provider }\end{array}$ & $\begin{array}{l}1 \text { Public } \\
\text { Provider }\end{array}$ & $\begin{array}{c}1 \text { Comp. } \\
\text { Care }\end{array}$ \\
\hline & \multicolumn{5}{|c|}{ Panel A: National estimates } \\
\hline \multirow[t]{2}{*}{ 1.poor - non-poor } & -0.013 & -0.015 & $-0.039 *$ & 0.021 & 0.004 \\
\hline & $(0.010)$ & $(0.011)$ & $(0.020)$ & $(0.014)$ & $(0.019)$ \\
\hline \multirow[t]{2}{*}{ 2.near-poor - non-poor } & -0.004 & -0.014 & -0.007 & -0.012 & 0.004 \\
\hline & $(0.008)$ & $(0.008)$ & $(0.010)$ & $(0.009)$ & $(0.015)$ \\
\hline \multirow[t]{2}{*}{ 3.pooruk - non-poor } & 0.009 & -0.010 & -0.014 & -0.015 & -0.004 \\
\hline & $(0.008)$ & $(0.011)$ & $(0.016)$ & $(0.010)$ & $(0.019)$ \\
\hline $\mathbf{N}$ & 220882 & 150925 & 132836 & 132836 & 113643 \\
\hline \multirow[t]{2}{*}{ R-squared } & 0.041 & 0.023 & 0.127 & 0.123 & 0.038 \\
\hline & \multicolumn{5}{|c|}{ Panel B: 28 Urban Immunization Action Plan areas only: } \\
\hline \multirow[t]{2}{*}{ 1.poor - non-poor } & -0.007 & 0.000 & 0.009 & -0.008 & 0.026 \\
\hline & $(0.009)$ & $(0.010)$ & $(0.035)$ & $(0.027)$ & $(0.017)$ \\
\hline \multirow[t]{2}{*}{ 2.near-poor - non-poor } & -0.024 & -0.042 & $-0.050 *$ & -0.014 & -0.014 \\
\hline & $(0.013)$ & $(0.025)$ & $(0.025)$ & $(0.015)$ & $(0.020)$ \\
\hline \multirow[t]{2}{*}{ 3.pooruk - non-poor } & 0.017 & -0.012 & -0.017 & $-0.032 *$ & 0.003 \\
\hline & $(0.012)$ & $(0.019)$ & $(0.022)$ & $(0.016)$ & $(0.023)$ \\
\hline $\mathbf{N}$ & 78438 & 50303 & 43822 & 43822 & 38369 \\
\hline \multirow[t]{2}{*}{ R-squared } & 0.036 & 0.021 & 0.141 & 0.111 & 0.030 \\
\hline & \multicolumn{5}{|c|}{ Panel C: 17 states with the highest rate of uninsured kids in 1995-1997 } \\
\hline \multirow[t]{2}{*}{ 1.poor - non-poor } & 0.006 & 0.008 & 0.013 & -0.018 & 0.034 \\
\hline & $(0.014)$ & $(0.014)$ & $(0.025)$ & $(0.020)$ & $(0.023)$ \\
\hline \multirow[t]{2}{*}{ 2.near-poor - non-poor } & 0.002 & -0.013 & 0.002 & $-0.036^{*}$ & 0.026 \\
\hline & $(0.011)$ & $(0.010)$ & $(0.016)$ & $(0.015)$ & $(0.025)$ \\
\hline \multirow[t]{2}{*}{ 3.pooruk - non-poor } & 0.025 & 0.007 & 0.011 & $-0.047 * *$ & $0.047 *$ \\
\hline & $(0.013)$ & $(0.011)$ & $(0.015)$ & $(0.011)$ & $(0.023)$ \\
\hline $\mathbf{N}$ & 87107 & 57029 & 50040 & 50040 & 43451 \\
\hline R-squared & 0.033 & 0.017 & 0.137 & 0.147 & 0.032 \\
\hline
\end{tabular}


Appendix Table 3. Continued:

\begin{tabular}{lccccc}
\hline & 1 Provider (R) & 1 Provider & $\begin{array}{c}\text { 1 Private } \\
\text { Provider }\end{array}$ & $\begin{array}{c}\text { 1 Public } \\
\text { Provider }\end{array}$ & $\begin{array}{c}\text { 1 Comp. } \\
\text { Care }\end{array}$ \\
\hline \multicolumn{2}{c}{ Panel D: Hispanics only, in 9 states with large Hispanic population } \\
1.poor - non-poor & -0.012 & -0.014 & -0.007 & 0.036 & -0.023 \\
& $(0.037)$ & $(0.041)$ & $(0.040)$ & $(0.029)$ & $(0.050)$ \\
2.near-poor - non-poor & -0.026 & -0.043 & -0.010 & -0.003 & $-0.067^{*}$ \\
3.pooruk - non-poor & $(0.034)$ & $(0.028)$ & $(0.025)$ & $(0.023)$ & $(0.027)$ \\
& -0.008 & -0.014 & -0.013 & $-0.055^{* *}$ & -0.058 \\
N & $(0.033)$ & $(0.031)$ & $(0.055)$ & $(0.019)$ & $(0.034)$ \\
R-squared & 23362 & 15024 & 13038 & 13038 & 11911 \\
& 0.022 & 0.015 & 0.089 & 0.094 & 0.026 \\
\hline
\end{tabular}

${ }^{*}$ significant at $5 \% ; * *$ significant at $1 \%$. See notes to Table 3 in the text. 